\title{
Rate, determinants, and causes of stillbirth in Jordan: Findings from the Jordan Stillbirth and Neonatal Deaths Surveillance (JSANDS) system
}

Khulood K. Shattnawi ${ }^{1 *}$, Yousef S. Khader ${ }^{2}$, Mohammad S. Alyahya ${ }^{3}$, Nihaya Al-Sheyab ${ }^{4}$ and Anwar Batieha ${ }^{5}$

\begin{abstract}
Background: Annually, 2.6 million stillbirths occur around the world, with approximately 98\% occurring in low- and middle-income countries. The stillbirth rates in these countries are 10 times higher than the rates in high-income countries.

Methods: An electronic stillbirths and neonatal deaths surveillance system (JSANDS) was established in five large hospitals located in three of the largest cities in Jordan in August 2019. JSANDS was developed as a secure on-line data entry system to collect, organize, analyze, and disseminate data on stillbirths, neonatal deaths, and their contributing conditions. Data on births, stillbirths and their contributing conditions, and other demographic and clinical characteristics in the period between August 2019 - January 2020 were extracted and analyzed.

Results: A total of 10,328 births were registered during the reporting period. Of the total births, 102 were born dead (88 antepartum stillbirths and 14 intrapartum stillbirths), with a rate of 9.9 per 1000 total births. The main contributing fetal conditions of antepartum stillbirths were antepartum death of unspecified cause (33.7\%), acute antepartum event (hypoxia) (33.7\%), congenital malformations and chromosomal abnormalities (13.3\%), and disorders related to the length of gestation and fetal growth (10.8\%). The main contributing maternal conditions of antepartum stillbirths included complications of the placental cord and membranes (48.7\%), maternal complications of pregnancy (23.1\%), and maternal medical and surgical conditions (23.1\%). Contributing fetal conditions of intrapartum stillbirths included congenital malformations, deformations and chromosomal abnormalities, other specified intrapartum disorders, and intrapartum death of unspecified cause (33.3\% each). Contributing maternal conditions of intrapartum stillbirths included complications of the placental cord and membranes. In the multivariate analysis, small for gestational age (SGA) pregnancies were associated with a significant 3-fold increased risk of stillbirth compared to appropriate for gestational age (AGA) pregnancies.
\end{abstract}

Conclusions: Although the rate of stillbirth is lower than that in other countries in the region, there is an opportunity to prevent such deaths. While the majority of stillbirths occurred during the antepartum period, care should be taken for the early identification of high-risk pregnancies, including the early detection of SGA pregnancies, and ensuring adequate antenatal obstetric interventions.

Keywords: Stillbirth, Jordan, Rate, Determinants, Surveillance

\footnotetext{
* Correspondence: khuloods@just.edu.jo

'Maternal \& Child Health Nursing Department, Faculty of Nursing, Jordan University of Science and Technology, P.O.Box (3030, 22110 Irbid, Jordan Full list of author information is available at the end of the article
}

(c) The Author(s). 2020 Open Access This article is licensed under a Creative Commons Attribution 4.0 International License, which permits use, sharing, adaptation, distribution and reproduction in any medium or format, as long as you give appropriate credit to the original author(s) and the source, provide a link to the Creative Commons licence, and indicate if changes were made. The images or other third party material in this article are included in the article's Creative Commons licence, unless indicated otherwise in a credit line to the material. If material is not included in the article's Creative Commons licence and your intended use is not permitted by statutory regulation or exceeds the permitted use, you will need to obtain permission directly from the copyright holder. To view a copy of this licence, visit http://creativecommons.org/licenses/by/4.0/. The Creative Commons Public Domain Dedication waiver (http://creativecommons.org/publicdomain/zero/1.0/) applies to the data made available in this article, unless otherwise stated in a credit line to the data. 


\section{Background}

Stillbirth is considered a global public health problem, particularly in developing countries. The global burden of disease study reported a $47.0 \%$ decline in stillbirth rates between 1990 and 2015 [1]. Data extracted from registration systems from 157 countries reported that an estimate of 2.6 million stillbirths occurred annually and showed a reduction of $25.5 \%$ in stillbirth rates for the period 2000 until 2015 [2]. Approximately 98\% of these stillbirths occurred in low- and middle-income countries [3].

Regionally, a retrospective population-based study of stillbirth in a multi-ethnic Middle-Eastern population reported a stillbirth rate of 7.81 per 1000 total births [4]. The majority of stillbirths in the developing countries occur unexpectedly, without a clear cause [5]. It is difficult to confirm the cause because there are many factors that may contribute to the cause of a stillbirth; however, the literature has categorized contributing conditions into those related to maternal or fetal conditions [6]. Maducolil et al. reported that maternal factors comprised a $52.4 \%$ of total stillbirths in the Middle-Eastern population and included maternal hypertension, diabetes, and other medical disorders. The main fetal factors reported in the same study were intrauterine growth restriction followed by congenital anomalies [4].

One study in Jordan reported the stillbirth rate during the period 2011-2012 and showed a stillbirth rate of 10.6 per 1000 total births [7]. This study reported maternal diseases, unexplained immaturity, congenital anomalies, unexplained antepartum stillbirths, obstetric complications, placental conditions, and multiple births as the main contributing conditions of stillbirths.

The scarcity of data in Jordan on stillbirth is generally linked to the fact that stillbirths are not registered [8]. In addition, the existing sources of data on stillbirths are liable to biases. Therefore, improving a reporting system of stillbirth and neonatal deaths is critical for tracking progress and taking appropriate actions. As a result of this limitation, an electronic stillbirths and neonatal deaths surveillance system (JSANDS) was developed and established in five large hospitals in Jordan in August 2019. JSANDS was developed as a secure on-line data entry system to collect, organize, analyze, and disseminate reliable data on stillbirths, neonatal deaths, and their contributing conditions. In addition, the system registers births to use them as a denominator for mortality measures. The definitions of the stillbirths and neonatal deaths used in the system were based on the international standards set by the WHO and the CDC. To ensure comparability of mortality rates between different providers and to allow for international comparisons, births less than $24^{+0}$ weeks of gestation and terminations of pregnancy are not reported by JSANDS. This study used the data from JSANDS to determine the rate, determinants, and contributing conditions of stillbirths in Jordan.

\section{Methods}

This manuscript is reporting the results of the first phase of a larger study. The information on all deliveries and birth outcomes that were registered in JSANDS during the period from August 2019 to January 2020 was retrieved from the system. A team of researchers was assigned, one for each hospital, to monitor the delivery entries. As a result, all births and stillbirths that occurred in the five large hospitals were registered with a completeness of $100 \%$. Three hospitals were public hospitals, one was private, and one was a teaching hospital. The extracted data included sociodemographic characteristics of both parents, delivery information (i.e., mode of delivery, multiplicity, and gestational age), newborn information (status, birth weight, Apgar score) and contributing conditions of stillbirths.

In this study, stillbirth was defined as any fetal death that occurred at or after 24 gestational weeks. Stillbirths were categorized to antepartum (deaths occurring prior to labor) and intrapartum stillbirths (deaths that occur after the onset of labor but prior to birth). The stillbirth rate was calculated as the number of stillbirths per 1000 total live births and stillborn births.

Contributing conditions of stillbirths were determined based on the International Classification of DiseasesPerinatal Mortality (ICD-PM), which is derived from the 10th version of the International Classification of Diseases (ICD-10) developed by the WHO [9]. ICD-PM is a standardized classification for reporting perinatal deaths [9]. All health care professionals in the five hospitals were trained on how to assign the main contributing condition of death. The doctor (an obstetrician) who was responsible for the delivery of a stillbirth accompanied by a neonatologist who attended the delivery had the primary responsibility to complete the form for the stillbirth, assign the main contributing condition of death, and record the ICD-10 code accordingly. ICD-10 codes were used to provide a common language for reporting and monitoring diseases. This allows for comparing and sharing data in a consistent and standard manner between the 5 hospitals.

Contributing conditions of deaths related to fetal or maternal condition were registered. First, the main disease or condition in the fetus was determined, in which the single most important and main disease or condition of the fetus who died was entered. This was supported by reporting any other diseases or conditions in the fetus, if any. As there is no uniform protocol to evaluate and classify stillbirths in Jordan, malformations and chromosomal abnormalities were determined based on the attending obstetrician's and neonatologist's 
judgments of the obvious stillbirth malformations. According to the hospital's protocol for placental examination, visual examinations of the placentas and umbilical cords were performed. In addition, a detailed summary of every stillbirth was discussed in monthly death review committee meetings attended by obstetricians, neonatologists, and senior midwives and nurses. Second, the main maternal disease or condition affecting the fetus was reported. The "most important" maternal disease or condition affecting the fetus that made the greatest contribution to the fetal death was reported. Other maternal diseases or conditions affecting fetus, if any, were also reported in this section.

Data were described and analyzed using IBM SPSS version 24 (IBM Corp. Released 2016. IBM SPSS Statistics for Windows, Version 24.0. Armonk, NY: IBM Corp.). Data were described using means and standard deviations for continuous variables and rates and percentages for categorical data. The stillbirth rate was calculated as the number of stillbirths by 1000 total births. Fetal weight percentile was determined based on birth weight and fetal age for stillbirths. Fetal growth was categorized as small for gestational age (SGA) if $<10$ th percentile, appropriate for gestation if between 10th - 90th percentile, or large for gestation if $>90$ th percentile. The distributions of stillbirths according to studied characteristics, including birthweight for gestational age percentiles, were tested using the Chi-square test. Multivariate analysis using binary logistic regression was used to determine factors associated with stillbirth. A $p$ value of less than 0.05 was considered statistically significant.

The study was ethically approved by the Institutional Review Board (IRB) at Jordan University of Science and Technology (Ethical approval number 20,170,033). Permission from the Ministry of Health was received to access the data and use it for research purposes. To ensure the data confidentiality, the data were exported without identifying information, such as the name or phone number.

\section{Results}

\section{Women's demographic and maternal characteristics}

During the period from August 2019 to January 2020, a total of 9983 women gave birth to 10,328 babies. The women's ages ranged between 15 and 48 years, with a mean (SD) of 29.1 (6.1) years. The majority of women (81.0\%) were between 19 and 35 years of age, 2.5\% were younger than 19 years and $16.5 \%$ were older than 35 years. Table 1 shows the sociodemographic and maternal characteristics of the women.

\section{Stillbirth rate}

Of the total 10,328 births, 102 were stillborn (88 antepartum stillbirths and 14 intrapartum stillbirths). The overall stillbirth rate was 9.9 per 1000 total births. Table 2 shows the stillbirth rate according to the maternal, clinical and relevant characteristics. The stillbirth rate did not vary significantly according to health sector and mother's age, educational level, income, and working status. However, the rate varied significantly according to multiplicity, birthweight and gestational age. The rate per 1000 total births was significantly higher in multiple births than in single births (8.7 in single births, 24.1 in twins, 69.8 in triplets, and 375.0 in quadruplets). The stillbirth rate was much higher among small for gestational age (SGA) deliveries compared to appropriate for gestational age (AGA) deliveries.

\section{Determinants of stillbirths}

Of all studied factors, only birthweight for gestational age percentiles was significantly associated with the risk of stillbirth (Table 3). SGA pregnancies were associated with a significant 3-fold increased risk of stillbirth compared to AGA pregnancies.

\section{Contributing conditions of stillbirths}

Table 4 shows the main contributing conditions of antepartum stillbirths. The main leading contributing condition of antepartum stillbirths was an acute antepartum event (hypoxia), which contributed to $33.7 \%$ of antepartum stillbirths. One-third (33.7\%) of antepartum stillbirths had no specific cause. The second and third contributing conditions of antepartum stillbirths were congenital malformations and chromosomal abnormalities $(13.3 \%)$ and disorders related to length of gestation and fetal growth (10.8\%), respectively. Maternal conditions contributed to $39(47.0 \%)$ antepartum stillbirths. Complications of placenta cord and membranes contributed to $22.9 \%$, maternal complications of pregnancy contributed to $10.8 \%$, and maternal medical and surgical conditions contributed to $10.8 \%$ of antepartum stillbirths.

Table 5 shows the main contributing conditions of intrapartum stillbirths. Congenital malformations, deformations and chromosomal abnormalities contributed to $33.3 \%$ of intrapartum stillbirths, and other specified intrapartum disorders contributed to $33.3 \%$ of intrapartum stillbirths. The remaining intrapartum stillbirths had no specified cause. Complications of placenta cord and membranes contributed to $33.3 \%$ of intrapartum stillbirths.

\section{Discussion}

Stillbirth rates vary widely between countries. According to Frøen et al., stillbirths are not counted in 90 countries worldwide [10], making it difficult to estimate the true rates of stillbirth. In the current study, the incidence of stillbirth was found to be 9.9 per 1000 live births. This 
Table 1 The sociodemographic and maternal characteristics of the women in the study $(n=9983)$

\begin{tabular}{|c|c|}
\hline Variables & $\%$ \\
\hline \multicolumn{2}{|l|}{ Hospital } \\
\hline Private & 17.6 \\
\hline Teaching & 13.7 \\
\hline Ministry of Health & 68.7 \\
\hline \multicolumn{2}{|l|}{ Mother age (year) } \\
\hline$\leq 18$ & 2.5 \\
\hline $19-35$ & 81.0 \\
\hline$>35$ & 16.5 \\
\hline \multicolumn{2}{|c|}{ Mother Education Level } \\
\hline High school or less & 55.4 \\
\hline Diploma & 6.9 \\
\hline Bachelor & 24.2 \\
\hline Master or higher & 2.5 \\
\hline Unknown & 11.0 \\
\hline \multicolumn{2}{|l|}{ Total Income (JD) } \\
\hline$<500$ & 74.0 \\
\hline $500-<1000$ & 16.7 \\
\hline$\geq 1000$ & 2.1 \\
\hline Unknown & 7.2 \\
\hline \multicolumn{2}{|l|}{ Working status } \\
\hline Housewife & 89.6 \\
\hline Employed & 10.4 \\
\hline \multicolumn{2}{|l|}{ Mode of delivery } \\
\hline Vaginal & 51.2 \\
\hline Planned CS & 27.2 \\
\hline Emergency CS & 21.6 \\
\hline \multicolumn{2}{|l|}{ Multiplicity } \\
\hline Single & 97.4 \\
\hline Twin & 2.4 \\
\hline Triplet & 0.2 \\
\hline Quadruplet & 0.0 \\
\hline \multicolumn{2}{|l|}{ Gestational age } \\
\hline Full-term & 90.3 \\
\hline Preterm & 9.7 \\
\hline
\end{tabular}

rate is similar to the rate in Lebanon for the year 2015 (9.9) [11]. The rate is higher than the rate of 7.81 per 1000 births that was reported in a multi-ethnic MiddleEastern-based study [4] and the rates reported for the year 2015 for some other Arab countries, such as Libya (8.8 per 1000 live births), Oman (8.5 per 1000 live births), Qatar (5.8 per 1000 live births), and Kuwait (5.1 per 1000 live births) [11]. However, the rate was lower than the rate of 11.6 per 1000 live births that was reported in a previous Jordan study in 2012 [8] and the
2015 rates in other countries, such Syria (11.1), Saudia Arabia (13.9), Egypt (12.2), Iraq (15.5), and Jordan (10.5) [11]. This decline is promising and might be related to improvements in maternal health care services, yet there remains room for more improvement. Most of these stillbirths are preventable, and a greater decline in stillbirth rate is possible. To achieve lower rates, we need to address possible risk factors and possible contributing conditions of stillbirths.

Our study showed that SGA pregnancies and multiple gestations are risk factors of stillbirth. These are wellknown risk factors in the literature and are closely linked to stillbirths [12-14]. SGA may result from both fetal growth restriction and preterm birth, which are associated with placental dysfunction and subsequent poor fetal outcomes [2]. This increases the risk of both antepartum and intrapartum fetal deaths [2]. As stillbirth rates are very sensitive to access to high-quality antenatal health care [6], proper assessment and early identification of multiple gestations, gestational age, and birth weight may contribute to the decrease of the incidence of stillbirths.

Although advanced maternal age of $>35$ years was reported as a significant factor for increased stillbirth rate $[15,16]$, it was not found to be significant in the current study. The exact mechanism of the increase risk of stillbirth with advanced maternal age is not fully understood [17], which necessitates additional studies to determine the mechanism. However, some research suggested that advanced maternal age is associated with placental dysfunction, which may increase the risk of stillbirths [17], or to existing maternal medical conditions [18]. Nevertheless, of the existing evidence, the lack of relationship in this study between advanced maternal age and risk of stillbirth may be explained by the low percentage of mothers of advanced age in our sample.

Based on the WHO ICD-PM classification, the main two contributing fetal conditions of antepartum stillbirth in this study were antepartum death of unspecified cause and acute antepartum event (hypoxia), followed by congenital malformations and chromosomal abnormalities. Allanson et al. [19] have demonstrated the application of the WHO ICD-PM to perinatal deaths in two data sets from the UK and South Africa. Similar to our findings, they reported antepartum hypoxia events as the major causes of antepartum deaths for the South Africa data set. Maternal conditions that were associated with these deaths were mostly medical and surgical conditions. For the UK data set, the majority of antepartum deaths were unexplained deaths to healthy mothers. Antepartum hypoxia is one of the most significant problems contributing to stillbirths and neonatal deaths and can be caused by many conditions, such as placental insufficiency [20]. 
Table 2 Stillbirth rate according to the sociodemographic, maternal, clinical and relevant characteristics of the women and the birth characteristics

\begin{tabular}{|c|c|c|c|c|}
\hline Variables & Total births (\%) & Number of Stillbirths & Stillbirth rate per 1000 total births & $p$-value \\
\hline Hospital & & & & 0.928 \\
\hline Private & $1814(17.6)$ & 19 & 10.5 & \\
\hline Teaching & $1447(14.0)$ & 15 & 10.4 & \\
\hline Ministry of Health & $7067(68.4)$ & 68 & 9.6 & \\
\hline Mother age (year) & & & & 0.275 \\
\hline$\leq 18$ & $255(2.5)$ & 2 & 7.8 & \\
\hline $19-35$ & $8377(81.1)$ & 89 & 10.6 & \\
\hline$>35$ & $1696(16.4)$ & 11 & 6.5 & \\
\hline Mother Education Level & & & & 0.109 \\
\hline High school or less & $5702(55.2)$ & 59 & 10.3 & \\
\hline Diploma & $711(6.9)$ & 2 & 2.8 & \\
\hline Bachelor & $2502(24.2)$ & 26 & 10.4 & \\
\hline Master or higher & $259(2.5)$ & 0 & 0.0 & \\
\hline Unknown & $1154(11.2)$ & 15 & 13.0 & \\
\hline Total Income (JD) & & & & 0.905 \\
\hline$<500$ & $7633(73.9)$ & 75 & 9.8 & \\
\hline $500-<1000$ & $1718(16.6)$ & 19 & 11.1 & \\
\hline$\geq 1000$ & $217(2.1)$ & 2 & 9.2 & \\
\hline Unknown & $760(7.4)$ & 6 & 7.9 & \\
\hline Working status & & & & 0.869 \\
\hline Housewife & $9265(89.7)$ & 91 & 9.8 & \\
\hline Employed & $1063(10.3)$ & 11 & 10.3 & \\
\hline Multiplicity & & & & $<0.001$ \\
\hline Single & $9777(95.1)$ & 85 & 8.7 & \\
\hline Twin & $457(4.4)$ & 11 & 24.1 & \\
\hline Triplet & $43(0.4)$ & 3 & 69.8 & \\
\hline Quadruplet & $8(0.1)$ & 3 & 375.0 & \\
\hline Birthweight for gestational age & & & & $<0.001$ \\
\hline$<10$ th Percentile & $952(9.2)$ & 25 & 26.3 & \\
\hline 10th - 90th Percentile & $8304(80.4)$ & 70 & 8.4 & \\
\hline >90th Percentile & $1072(10.4)$ & 7 & 6.5 & \\
\hline Gender of baby & & & & 0.465 \\
\hline Female & $4791(46.4)$ & 51 & 10.6 & \\
\hline Male & $5533(53.6)$ & 51 & 9.2 & \\
\hline
\end{tabular}

Congenital malformation was reported constantly

Table 3 The association between birthweight for gestational age percentiles and stillbirth

OR $\quad 95 \%$ Confidence Interval $p$-value

Birthweight for gestational age

\begin{tabular}{lllll}
$<10$ th Percentile & 3.2 & 2.0 & 5.0 & $<0.001$ \\
10th - 90th Percentile & Reference & & & \\
$>$ 90th Percentile & 0.8 & 0.4 & 1.7 & 0.518 \\
\hline
\end{tabular}

across many classification systems [6], which could be preventable by the use of prenatal folic acid supplements, which have been proved to decrease the incidence of congenital abnormalities such as neural tube defects [21].

Complications of the placental cord and membranes were identified as the main contributing maternal conditions of stillbirth in our study. Previous studies showed that a significant percentage of stillbirths arises from 
Table 4 Main contributing conditions of antepartum stillbirths

\begin{tabular}{lr}
\hline Contributing fetal conditions & N (\%) \\
\hline A1-Congenital malformations and chromosomal & $11(13.3 \%)$ \\
A2-Infection & $2(2.4 \%)$ \\
A3-Acute antepartum event (hypoxia) & $28(33.7 \%)$ \\
A4-Other specified antepartum disorder & $5(6.0 \%)$ \\
A5-Disorders related to length of gestation & $9(10.8 \%)$ \\
and fetal growth & \\
A6-Antepartum death of unspecified cause & $28(33.7 \%)$ \\
Total & $83(100.0 \%)$ \\
Contributing maternal conditions & \\
M1-Complications of placenta cord and membranes & $19(22.9 \%)$ \\
M2-Maternal complications of pregnancy & $9(10.8 \%)$ \\
M3-Other complications of labor and delivery & $2(2.4 \%)$ \\
M4-Maternal medical and surgical conditions & $9(10.8 \%)$ \\
No maternal cause & $44(53.0 \%)$ \\
\hline
\end{tabular}

placental problems $[15,22]$. Because of the inadequate oxygen supply to the fetus, placental dysfunction is linked to intrauterine growth restriction, preterm birth, and birth defects [23], which significantly increase the perinatal mortality and morbidity. This explains why SGA pregnancies are considered the main contributing factors of stillbirths.

Intrapartum stillbirths were relatively few in our study; however, they were significant in highlighting a very important contributing condition of stillbirth. Fetal contributing conditions of the intrapartum stillbirths included congenital malformations deformations and chromosomal abnormalities, other specified intrapartum disorder, and intrapartum death of unspecified cause. Maternal contributing conditions of intrapartum stillbirths included complications of the placental cord and membranes. The majority of these deaths could be prevented with reasonably priced interventions [24]. Bhutta and others proposed a basic package of antenatal interventions to reduce the incidence of antepartum and

Table 5 Main contributing conditions of intrapartum stillbirths

\begin{tabular}{ll}
\hline Contributing fetal conditions & N (\%) \\
\hline $\begin{array}{l}\text { I1-Congenital malformations, deformations } \\
\text { and chromosomal abnormalities }\end{array}$ & $4(33.3 \%)$ \\
I5-Other specified intrapartum disorder & $4(33.3 \%)$ \\
I7-Intrapartum death of unspecified cause & $4(33.3 \%)$ \\
Total & $12(100 \%)$ \\
Contributing maternal conditions & \\
M1-Complications of placenta cord and & $4(33.3 \%)$ \\
membranes & $8(66.7 \%)$ \\
\hline
\end{tabular}

intrapartum stillbirths. The package includes periconceptional folic acid supplementation, prevention of malaria, detection and management of syphilis during pregnancy, and basic and comprehensive emergency obstetric care [25]. Other interventions may include testing of high-risk pregnancies, ultrasonographic monitoring, and iatrogeneic deliveries [26]. As there is no clear evidence that ultrasonographic monitoring is harmful during pregnancy [27], it could be used with high-risk pregnancies for its many presumed benefits, including better estimation of gestational age, earlier detection of multiple pregnancies, placental abnormalities, fetal malformation and intrauterine fetal growth restriction [27].

The antepartum stillbirths reflect the quality that women receive during the antenatal period, while the intrapartum stillbirths reflect the quality of care that they receive during delivery [28]. The $\mathrm{WHO}$ has reported that deficiencies in the quality of antenatal care play a significant role in increasing the stillbirth rate [29]. Research has documented a significant decrease in stillbirths with higher quality antenatal care, women's education, and regular antenatal visits, and recommended more involvements of the health care provider in teaching mothers about the danger signs of pregnancy rather than providing only the basic health care assessments, such as measuring their blood pressure [30].

Maternal mortality and stillbirth are strongly correlated. It is imperative, therefore, to increase our attention for stillbirths and preterm birth interventions, which will positively impact the maternal and newborn health outcomes [31]. Investing in the health care system and providing good-quality and timely maternal services may prevent a significant ratio of stillbirths [32]. In interpretation of the study findings, one should consider that the study of specific causes of stillbirth has been hampered by lack of investigations such as fetal autopsy and genetic evaluation.

\section{Conclusions}

Although the rate of stillbirth is declining and is lower than that in other countries in the region, there is an opportunity to prevent such deaths. While the majority of stillbirths occurred during the antepartum period, care should be taken for the early identification of high-risk pregnancies, including the early detection of SGA pregnancies, and ensuring adequate antenatal obstetric interventions. SGA pregnancies and multiple gestations are reported as risk factors in the current study; therefore, efforts must be directed toward early prediction of these risks so that appropriate and timely interventions may be implemented to reduce stillbirths. This study reported the findings of stillbirths' data extracted from a national neonatal and stillbirth surveillance system. As the majority of stillbirths and neonatal deaths are not 
reported in Jordan, investing in the health information systems to improve data registration will encourage appropriate use of interventions to reduce stillbirth rates.

\section{Abbreviations}

JSANDS: Jordan Stillbirth and Neonatal Surveillance.; ICD-PM: International Classification of Diseases-Perinatal Mortality.

\section{Acknowledgements}

Not applicable.

\section{Authors' contributions}

K.K.S: Data collection, Writing- Original draft preparation, Reviewing and Editing. Y.K.: Principal Investigator, Conceptualization, Methodology, Project Administration, Funding Acquisition. M. A.: Data collection, Writing, Reviewing and Editing. N.A.: Data collection, Writing, Reviewing and Editing A.B.: Data collection, Conceptualization, Writing, Reviewing and editing. All authors have approved the final version of the manuscript.

\section{Funding}

This research is supported and funded by the International Development Research Centre/Canada (IDRC) and the United Nations International Children's Emergency Fund (UNICEF). The funding source had no role other than financial support.

\section{Availability of data and materials}

The datasets used and/or analyzed during the current study are available from the corresponding author on reasonable request.

\section{Ethics approval and consent to participate}

The study was ethically approved by the Institutional Review Board (IRB) at Jordan University of Science and Technology (Ethical approval number 20170033). To ensure the data confidentiality, data were exported without identifying information, such as the name and phone number.

\section{Consent for publication}

Not applicable.

\section{Competing interests}

The authors declare that they have no conflicts of interest.

\section{Author details}

${ }^{1}$ Maternal \& Child Health Nursing Department, Faculty of Nursing, Jordan University of Science and Technology, P.O.Box (3030, 22110 Irbid, Jordan. ${ }^{2}$ Department of Community Medicine, Public Health and Family Medicine, Faculty of Medicine, Jordan University of Science \& Technology, 22110 Irbid, Jordan. ${ }^{3}$ Department of Health Management and Policy, Faculty of Medicine, Jordan University of Science and Technology, P.O. Box 3030, 22110 Irbid, Jordan. ${ }^{4}$ Allied Medical Sciences Department/Faculty of Applied Medical Sciences, the Faculty of Nursing, Jordan University of Science and Technology, P.O. Box 3030, 22110 Irbid, Jordan. ${ }^{5}$ Department of Public Health, Jordan University of Science and Technology, Irbid, Jordan.

\section{Received: 7 April 2020 Accepted: 18 September 2020}

Published online: 29 September 2020

\section{References}

1. GBD. Global, regional, national, and selected subnational levels of stillbirths, neonatal, infant, and under-5 mortality, 1980-2015: a systematic analysis for the Global Burden of Disease Study 2015. Lancet. 2016 [cited 2020 Mar 20]; 388(10053):1725-74. Available from: https://www.thelancet.com/action/ showPdf?pii=S0140-6736\%2816\%2931575-6.

2. Blencowe H, Cousens S, Jassir FB, Say L, Chou D, Mathers C, et al. National, regional, and worldwide estimates of stillbirth rates in 2015, with trends from 2000: A systematic analysis. Lancet Glob Heal. 2016;4(2):e98-108. Available from: https://doi.org/10.1016/S2214-109X(15)00275-2.

3. World Health Organization (WHO). Making every baby count: audit and review of stillbirths and neonatal deaths. Geneva: WHO; 2016. Retrieved from: http://apps.who.int/iris/bitstream/10665/249523/1/9789241511223eng.pdf?ua=1. Accessed 11 July 2020.
4. Maducolil MK, Abid H, Lobo RM, Chughtai AQ, Afzal AM, Saleh HAH, et al. Risk factors and classification of stillbirth in a Middle Eastern population: A retrospective study. J Perinat Med. 2018;46(9):1022-7. https://doi.org/10.1515/jpm-2017-0274.

5. Tavares Da Silva F, Gonik B, McMillan M, Keech C, Dellicour S, Bhange S, et al. Stillbirth: Case definition and guidelines for data collection, analysis, and presentation of maternal immunization safety data. Vaccine. 2016 [cited 2020 Feb 12];34(49): 6057-68. Available from: http//uww.ncbi.nlm.nih.gov/pubmed/27431422.

6. Lawn JE, Blencowe H, Waiswa P, Amouzou A, Mathers C, Hogan D, et al. Stillbirths: Rates, risk factors, and acceleration towards 2030. Lancet. 2016 387(10018):587-603.

7. Khader YS, Batieha A, Khader A, Hamadneh S. Stillbirths in Jordan: rate, causes, and preventability. J Matern Neonatal Med. 2018 Sep 25 [cited 2019 Mar 21];18. Available from: http://www.ncbinlm.nih.gov/pubmed/30153760.

8. Alyahya MS, Khader YS. Health care professionals' knowledge and awareness of the ICD-10 coding system for assigning the cause of perinatal deaths in Jordanian hospitals. J Multidiscip Healthc. 2019;12:149-57.

9. World Health Organization (WHO). The WHO application of ICD-10 to deaths during the perinatal period: ICD-PM. Geneva: WHO; 2016. p. 1-88. Retrieved from: https://apps.who.int/iris/bitstream/handle/10665/249515/ 9789241549752-eng.pdf. Accessed 11 July 2020.

10. Frøen JF, Cacciatore J, McClure EM, Kuti O, Jokhio AH, Islam M, et al. Stillbirths: Why they matter. Lancet. 2011;377(9774):1353-66.

11. WHO. Global Health Observatory data repository: Stillbirth rate - Data by country. WHO. World Health Organization; 2017 [cited 2020 Mar 22]. Available from: https://apps.who.int/gho/data/view.main.GSWCAH06v.

12. Devi KS, Aziz N, Gala A, Surapaneni T, Hira HDN. B. Incidence of stillbirths and risk factors at a tertiary perinatal center in Southern India: retrospective observational study. Int J Gynecol Reprod Sci. 2018;1(January 2010):14-22.

13. WHO. WHO | Stillbirths. WHO. World Health Organization; 2016 [cited 2020 Feb 4]. Available from: https://www.who.int/maternal_child_adolescent/ epidemiology/stillbirth/en/.

14. WHO. Newborns: reducing mortality. WHO. 2017 [cited 2018 Jan 5]; Available from: http://www.who.int/mediacentre/factsheets/fs333/en/.

15. Flenady V, Koopmans L, Middleton P, Frøen JF, Smith GC, Gibbons K, et al. Major risk factors for stillbirth in high-income countries: A systematic review and meta-analysis. Lancet. 2011;377(9774):1331-40. Available from: https:// doi.org/10.1016/S0140-6736(10)62233-7.

16. Lean SC, Denicott H, Jones RL, Heazell AP. Advanced matemal age and adverse pregnancy outcomes A systematic review and metaanalysis PLoS One 2017;12(10):1-15.

17. Lean SC, Heazell AEP, Dilworth MR, Mills TA, Jones RL. Placental Dysfunction Underlies Increased Risk of Fetal Growth Restriction and Stillbirth in Advanced Maternal Age Women. Sci Rep. 2017 Dec 29 [cited 2020 Mar 23];7(1):9677. Available from: http://www.nature.com/articles/s41598-017-09814-w.

18. Walker KF, Bradshaw L, Bugg GJ, Thornton JG. Causes of antepartum stillbirth in women of advanced maternal age. Eur J Obstet Gynecol Reprod Biol. 2016 Feb [cited 2020 Mar 23];197:86-90. Available from: https:// linkinghub.elsevier.com/retrieve/pii/S0301211515004315.

19. Allanson ER, Tunçalp, Gardosi J, Pattinson RC, Francis A, Vogel JP, et al. The WHO application of ICD-10 to deaths during the perinatal period (ICD-PM): results from pilot database testing in South Africa and United Kingdom. BJOG An Int J Obstet Gynaecol. 2016;123(12):2019-28.

20. Thompson LP, Crimmins S, Telugu B, Turan S. Intrauterine hypoxia: clinical consequences and therapeutic perspectives. Res Reports Neonatol. 2015; 5(September 2015):79-89.

21. Gaskins AJ, Rich-Edwards JW, Hauser R, Williams PL, Gillman MW, Ginsburg $E S$, et al. Maternal prepregnancy folate intake and risk of spontaneous abortion and stillbirth. Obstet Gynecol. 2014 Jul [cited 2020 Mar 23];124(1): 23-31. Available from: http://www.ncbin.nlm.nih.gov/pubmed/24901281.

22. Ray JG, Urquia ML. Risk of stillbirth at extremes of birth weight between 20 to 41 weeks gestation. J Perinatol. 2012;32(11):829-36.

23. Malhotra A, Allison BJ, Castillo-Melendez M, Jenkin G, Polglase GR, Miller SL. Neonatal Morbidities of Fetal Growth Restriction: Pathophysiology and Impact. Front Endocrinol (Lausanne). 2019 [cited 2020 Feb 23];10:55. Available from: http://www.ncbi.nlm.nih.gov/pubmed/30792696.

24. Khader YS, Alyahya M, Batieha A. Perinatal and Neonatal Mortality in Jordan. In: Handbook of Healthcare in the Arab World. 2019. p. 1-22.

25. Bhutta ZA, Yakoob MY, Lawn JE, Rizvi A, Friberg IK, Weissman E, et al. Stillbirths: what difference can we make and at what cost? Lancet. 2011 Apr 30 [cited 2020 Feb 20]; 377(9776):1523-38. Available from: http://www.ncbi.nlm.nih.gov/pubmed/21496906.

26. Page JM, Silver RM. Interventions to prevent stillbirth. Semin Fetal Neonatal Med. 2017;22(3):135-45. Available from: https://doi.org/10.1016/j.siny.2017.02.010. 
27. Haws RA, Yakoob M, Soomro T, Menezes EV, Darmstadt GL, Bhutta ZA Reducing stillbirths: Screening and monitoring during pregnancy and labour. BMC Pregnancy Childbirth. 2009;9(SUPPL. 1):1-48.

28. Goldenberg RL, McClure EM, Bann CM. The relationship of intrapartum and antepartum stillbirth rates to measures of obstetric care in developed and developing countries. Acta Obstet Gynecol Scand. 2007;86(11):1303-9.

29. WHO. WHO Recommendations on Antenatal Care for a Positive Pregnancy Experience. Summary: Highlights and Key Messages from the World Health Organization's 2016 Global Recommendations for Routine Antenatal Care. 2018 [cited 2020 Mar 16]. Available from: www.mcsprogram.org.

30. Afulani PA. Determinants of stillbirths in Ghana: Does quality of antenatal care matter? BMC Pregnancy Childbirth. 2016;16(1):1-18.

31. Lawn JE, Gravett MG, Nunes TM, Rubens CE, Stanton C. Global report on preterm birth and stillbirth ( 1 of 7): Definitions, description of the burden and opportunities to improve data. BMC Pregnancy Childbirth. 2010;10(SUPPL. 1).

32. Neogi SB, Sharma J, Negandhi P, Chauhan M, Reddy S, Sethy G. Risk factors for stillbirths: How much can a responsive health system prevent? BMC Pregnancy Childbirth. 2018;18(1):1-10.

\section{Publisher's Note}

Springer Nature remains neutral with regard to jurisdictional claims in published maps and institutional affiliations.

Ready to submit your research? Choose BMC and benefit from:

- fast, convenient online submission

- thorough peer review by experienced researchers in your field

- rapid publication on acceptance

- support for research data, including large and complex data types

- gold Open Access which fosters wider collaboration and increased citations

- maximum visibility for your research: over $100 \mathrm{M}$ website views per year

At BMC, research is always in progress.

Learn more biomedcentral.com/submissions 